\title{
Ação do insecticida tiametoxame aplicado às sementes na emergência e vigor de plântulas de Vigna unguiculata (L.) Walp
}

\section{Action of thiamethoxam insecticide applied to seeds on the emergence and vigor of Vigna unguiculata (L.) Walp seedlings}

\author{
Rafael de Q. Costa1 ${ }^{1}$, Jerffson L. Santos ${ }^{1, *}$, John S. Portoํ․, Ramon C. de Vasconcelos², \\ Anne C. V. Cangussu ${ }^{1}$ e Otoniel M. Morais ${ }^{2}$ \\ 1 Programa de Pós-Graduação em Agronomia, Universidade Estadual do Sudoeste da Bahia, Campus de Vitória da Conquista, Estrada do Bem Querer, km 04, Vitória da Conquista - BA. CEP: \\ 45083-900, Brasil \\ 2 Professor Doutor, Departamento de Fitotecnia e Zootecnia, Universidade Estadual do Sudoeste da Bahia, Campus de Vitória da Conquista, Estrada do Bem Querer, km 04, Vitória da Conquista \\ -BA. CEP: 45083-900, Brasil \\ ( ${ }^{\star} E$-mail: je.lucas@hotmail.com) \\ http://dx.doi.org/10.19084/RCA16151
}

Recebido/received: 2016.11 .17

Recebido em versão revista/received in revised form: 2016.12 .20

Aceite/accepted: 2017.02.10

\section{R E S U M O}

Objetivou-se, neste estudo, avaliar os efeitos do tiametoxame sobre a emergência e vigor de plântulas de feijão-caupi oriundas de diferentes lotes e épocas de sementeira. As sementes de feijão-caupi, cv. 'Nova era', foram tratadas com tiametoxame nas doses 0,$00 ; 0,07 ; 0,14 ; 0,21 ; 0,28$ e 0,35 g. i.a. $\mathrm{L}^{-1}$. O delineamento adotado consistiu em blocos casualizados, em esquema fatorial $2 \times 2 \times 6$, onde o primeiro fator foram lotes das colheitas 2013/2014 e 2014/2015, o segundo fator duas épocas de sementeira, verão e inverno, e o terceiro fator as doses de tiametoxame. Os parâmetros avaliados foram: porcentagem de emergência, índice de velocidade de emergência, comprimento da parte aérea e raiz de plântula, e massa seca da parte aérea e raiz de plântula. Ocorreu interação entre os lotes e a época de sementeira para as variáveis massa seca de parte aérea e da raiz e entre as doses e a época de sementeira para a emergência e índice de velocidade de emergência. O produto tiametoxame estimulou o desempenho fisiológico de sementes de feijão-caupi, ocorrendo efeitos positivos no crescimento e assimilação de matéria seca pelas raízes, e melhor desempenho inicial e estabelecimento uniforme das plântulas no inverno.

Palavras-chave: Fabaceae, feijão-caupi, germinação, inseticida, bioativador, fisiologia do desenvolvimento.

\begin{abstract}
A B S T R A C T
The aim of this study was to evaluate the effects of thiamethoxam on the emergence and vigor of cowpea seedlings. The cowpea seeds, cv. 'Nova era', were treated with the active ingredient thiamethoxam at dosages of $0.07 ; 0.14 ; 0.21 ; 0.28 \mathrm{e}$ $0.35 \mathrm{~g}$ a.i. $\mathrm{L}^{-1}$. The experimental design used was a randomized block in factorial $2 \times 2 \times 6$, where the first factor were lots of seasons 2013/2014 and 2014/2015, the second factor the two sowing seasons, summer and winter, and the third factor the doses of thiamethoxam. The parameters evaluated were: Percentage emergency, emergency speed index, shoot length and seedling root, and dry weight of shoot and seedling root. There was interaction between the lots and the sowing for the dry mass variable of shoot and root and between doses and the time of planting to emergence and emergence speed index. The insecticide thiamethoxam stimulates the physiological performance of cowpea seeds, occurring positive effects on growth and assimilation of dry matter by the roots, and better initial performance and uniform establishment of seedlings in the winter.
\end{abstract}

Keywords: Fabaceae, cowpea germination, insecticide, bioactivator, developmental physiology. 


\section{INTRODUÇÃO}

O feijão-caupi (Vigna unguiculata (L.) Walp) é uma leguminosa (Fabaceae) de ampla distribuição mundial, encontrada principalmente nas regiões tropicais, cujas características edafoclimáticas assemelham-se às do seu provável centro de origem, a África (Brito et al., 2009).

Entre as leguminosas, o feijão-caupi destaca-se pela sua rusticidade e é cultivado principalmente nos países da África, América Latina e Ásia. No Brasil, é tradicionalmente cultivado, e de grande importância socioeconómica nas regiões Norte e Nordeste (Freire Filho et al., 2011). É uma planta versátil fazendo parte fundamental da dieta alimentar, tanto na zona rural como urbana. A sua exploração é feita principalmente por pequenos agricultores, em sistema de cultivo predominantemente de sequeiro, com utilização de cultivares tradicionais e emprego de baixa tecnologia em todo o processo produtivo, o que se reflete em baixa produtividade (Silva et al., 2014).

O uso de sementes de alta qualidade é o fator fundamental para a formação de um estande uniforme, propiciando a maximização da ação dos demais insumos e fatores de produção utilizados na lavoura (Souza et al., 2007). Por isso, o tratamento de sementes com inseticidas é cada vez mais comum, não só com o intuito de proteção das sementes, mas principalmente, daqueles que possuem atuação fisiológica nas plantas visando melhorar o seu desempenho inicial no campo, ou durante o seu ciclo vegetativo, resultando um maior aproveitamento do seu potencial produtivo (Castro et al., 2008; Lemes et al., 2015).

A descoberta da molécula tiametoxame, que pertence ao grupo dos neonicotinóides, trouxe novas perspectivas para a agricultura, principalmente para o tratamento de sementes dado que diversos estudos têm mostrado a eficiência do inseticida como um bioativador (Acevedo e Clavijo, 2008; Lauxen et al., 2010).

Os bioativadores são substâncias naturais de origem vegetal, que possuem ações semelhantes às dos principais reguladores vegetais. Essas substâncias atuam na expressão dos genes responsáveis pela síntese e ativação de enzimas metabólicas, relacionadas com o crescimento da planta, alterando a produção de aminoácidos precursores de hormonas vegetais. Com maior produção de hormonas, a planta apresenta maior vigor, germinação e desenvolvimento das raízes (Castro et al., 2008). Por apresentar efeito bioativador a ação do tiametoxame na germinação de sementes reduz o tempo requerido para o estabelecimento da cultura no campo, diminuindo os efeitos negativos da competição com as ervas daninhas (Cataneo, 2008).

O tratamento de sementes com tiametoxame em feijão-caupi ainda não foi suficientemente estudado, necessitando de informações para que o uso desse inseticida apresente o efeito esperado na qualidade das suas sementes e no ciclo da cultura. Perante o exposto, propostas de trabalho que melhorem o desempenho das plantas no campo são de extrema importância, dado o perfil atual do sistema de produção da cultura que envolve baixo uso de tecnologia. Desta forma, os objetivos deste estudo consistiram em avaliar a ação do inseticida/ bioactivador: i) sobre a emergência e vigor de plântulas de feijão-caupi; ii) qual a relação do efeito com a época de sementeira e iii) qual a dose de tiametoxame mais eficaz por cada época de sementeira.

\section{MATERIAL E MÉTODOS}

O trabalho foi conduzido em estufa e no laboratório de tecnologia e produção de sementes, do Departamento de Fitotecnia e Zootecnia, da Universidade Estadual do Sudoeste da Bahia (UESB), campus de Vitória da Conquista, BA.

Foram utilizadas sementes de feijão-caupi, cultivar 'Nova Era', correspondente a dois lotes distintos de acordo com a época em que foram colhidas, 2013/2014 e 2014/2015. As sementes foram tratadas com o produto de nome comercial Cruiser ${ }^{\circledR} 350$ FS contendo 35 g i.a. $\mathrm{L}^{-1}$ de tiametoxame. Cinco concentrações do produto foram preparadas para tratar as sementes, onde a testemunha consistia apenas de água destilada. As doses aplicadas nas sementes foram 0,$00 ; 0,07 ; 0,14 ; 0,21 ; 0,28$ e 0,35 g i.a. de tiametoxame por litro, de acordo com metodologia adotada por Lauxen et al. (2010).

O delineamento experimental utilizado consistiu em blocos ao acaso, em esquema fatorial $2 \times 2 \times 6$, 
cujo primeiro fator foi referente às colheitas 2013/2014 e 2014/2015, identificados como colheita 1 e colheita 2, respectivamente. O segundo fator foram as duas épocas de sementeira, uma realizada no inverno e outra no verão, e o terceiro fator foram as seis doses de tiametoxame.

No momento da aplicação do inseticida, a fim de proporcionar uma calda homogénea, a quantidade de cada produto foi diluída em água destilada. A homogeneização da calda com as sementes foi realizada em sacos plásticos de $1,5 \mathrm{~kg}$ de capacidade. O conjunto foi agitado durante $2 \mathrm{~min}$ de modo a cobrir as sementes, com posterior secagem à sombra. Após esse procedimento o efeito do produto sobre as sementes foi avaliado por meio dos seguintes parâmetros:

i) Porcentagem de emergência (EM) - Foram semeadas 100 sementes por cada modalidade (dose de inseticida), distribuídas por quatro repetições de 25 sementes. A porcentagem de emergência foi obtida considerando as plântulas emergidas de acordo com as Regras para Análise de Sementes (Brasil, 2009).

ii) Índice de velocidade de emergência (IVE) - foi realizado em conjunto com o teste de emergência, com base na contagem de plântulas emergidas diariamente, até à estabilização da emergência das plântulas. A equação do IVE foi feita com base na equação proposta por Maguire (1962): IVE $=\left(E_{1} / N_{1}+\right.$ $\left.\mathrm{E}_{2} / \mathrm{N}_{2}+\ldots \mathrm{E}_{\mathrm{n}} / \mathrm{N}_{\mathrm{n}}\right)$, em que $\mathrm{E}_{1}, \mathrm{E}_{2}$ e $\mathrm{E}_{\mathrm{n}}$ são o número de plântulas que emergiram na primeira, na segunda e na última contagem e $\mathrm{N}_{1}, \mathrm{~N}_{2}$ e $\mathrm{N}_{\mathrm{n}}$ são o número de dias após a sementeira na primeira, na segunda e na última contagem;

iii) Comprimento da parte aérea e raiz (CPA e CR) - As medidas de comprimento foram obtidas com auxílio de uma régua milimétrica em 10 plântulas de cada repetição por tratamento, sendo as médias expressas em centímetros;

iv) Massa seca da parte aérea e raiz (MSPA e MSR) Em estufa de circulação forçada de ar, com temperatura de $65^{\circ} \mathrm{C}$, durante $48 \mathrm{~h}$, determinou-se o peso seco das plântulas obtidas em cada tratamento.

Os dados obtidos foram submetidos aos testes de homogeneidade das variâncias e normalidade dos erros. Em seguida, foi realizada a análise de variância pelo teste $\mathrm{F}$, e as médias, quando significativas, foram comparadas pelo teste de Tukey, ao nível de $5 \%$ de probabilidade. Além disso, foi aplicado teste de regressão para verificar a interação entre os fatores, por meio do software estatístico Sisvar ${ }^{\circledR}$ versão 5.3 (Ferreira, 2011).

\section{RESULTADOS E DISCUSSÃO}

Observaram-se diferenças significativas para quase todas as variáveis estudadas, com exceção para o comprimento da raiz (CR) e massa seca da raiz (MSR) para o fator colheita e CR para o fator sementeira. Em relação ao efeito das doses não se registaram diferenças significativas para o comprimento e massa seca da parte aérea (CPA, MSPA). Observou-se interação entre os fatores colheita e época de sementeira para os parâmetros MSPA e MSR, e entre os fatores doses e a época de sementeira para o IVE e EM. Não houve interação tripla em nenhum parâmetro avaliado (Quadro 1).

Verificou-se efeito isolado da colheita para as características CPA, IVE e EM (Quadro 2A). Foi possível observar que as sementes da colheita 2 apresentaram comprimento da parte aérea superior ao das sementes da colheita 1, no entanto, de acordo com os valores obtidos para os parâmetros IVE e EM as sementes da colheita 1 formaram plântulas mais vigorosas. De acordo com Costa et al. (2013), a emergência é influenciada pelo vigor das sementes, que é manifestado com maior evidência em campo, já que nessas condições as sementes nem sempre encontram um ambiente propício para germinação e crescimento e desenvolvimento das plântulas.

Destacando-se apenas a interferência de um único fator (colheita), os resultados obtidos sinalizaram que apesar das sementes da colheita 2 indicar em valor elevado para o CPA, esta demonstrou menor desempenho em formar um estande rápido e uniforme, em comparação a sementes da colheita 1. A diferença na qualidade fisiológica das sementes entre os níveis desse fator (colheita 1 e colheita 2) pode ser atribuída principalmente, segundo Aguero et al. (1997), aos efeitos das condições ambientais prevalecentes na fase de maturação e colheita das sementes. Da mesma maneira, Carvalho e Nakagawa (2012) discorrem 
Quadro 1 - Resumo da análise de variância referente às características de comprimento da parte aérea (CPA), comprimento de raiz (CR), massa seca da parte aérea (MSPA), massa seca de raiz (MSR), índice de velocidade de emergência (IVE) e porcentagem de emergência (EM) de sementes de feijão-caupi (Vigna unguiculata (L.) Walp) tratadas com tiametoxame

\begin{tabular}{lccccccc}
\hline \multirow{2}{*}{ F.V. } & GL & \multicolumn{7}{c}{ Quadrados Médios } \\
\cline { 3 - 8 } & & CPA & CR & MSPA & MSR & IVE & EM \\
\hline Colheita & 1 & $4,352^{*}$ & 0,756 & $2708,738^{*}$ & 33,658 & $0,948^{*}$ & $975,375^{*}$ \\
Sementeira & 1 & $7,238^{*}$ & 10,231 & $25600,214^{*}$ & $1937,157^{*}$ & $171,521^{*}$ & $1380,167^{*}$ \\
Doses & 5 & 0,396 & $20,727^{*}$ & 55,328 & $227,493^{*}$ & $0,408^{*}$ & $191,792^{*}$ \\
Colheita*doses & 5 & 0,354 & 8,294 & 24,825 & 150,683 & 0,153 & 12,950 \\
Colheita*sementeira & 1 & 0,008 & 7,415 & $3346,009^{*}$ & $557,293^{*}$ & 0,094 & 40,042 \\
Doses*sementeira & 5 & 0,427 & 2,897 & 96,596 & 154,926 & $0,362^{*}$ & $350,592^{*}$ \\
Colheita*doses*sementeira & 5 & 0,326 & 7,729 & 51,462 & 31,840 & 0,202 & 68,817 \\
Bloco & 3 & 0,940 & 2,572 & 133,693 & 20,720 & 0,381 & 141,750 \\
Resíduo & 69 & 0,477 & 5,644 & 54,978 & 69,780 & 0,141 & 42,438 \\
\hline CV (\%) & & 8,62 & 15,04 & 8,10 & 18,85 & 9,43 & 7,74 \\
\hline
\end{tabular}

* significativo pelo teste $\mathrm{F}, 5 \%$, respetivamente.

que dependendo da época em que as sementes são colhidas estas podem apresentar menor vigor.

Apesar da cultivar estudada possuir ampla aclimatação em região semiárida, a variação da época de sementeira resultou em divergências no desempenho das plântulas, proporcionando CPA superior no verão em relação às de inverno (Quadro 2B). Peixoto et al. (2000), salientam que a época de sementeira afeta a arquitetura e desenvolvimento da planta, ocasionando alterações na sua altura. Essa característica está relacionada com a cultivar, sendo dependente das condições bioclimáticas.

As diferenças na qualidade fisiológica das sementes de cada colheita, evidenciando distintos desempenhos das sementes quando submetidas a condições ambientais divergentes, demonstram que as épocas de cultura influenciaram o desenvolvimento dos dois lotes no campo. Esses resultados corroboram com a afirmação de Motta et al. (2002), onde relatam que a qualidade fisiológica de sementes de soja (Glycine max L.) foi influenciada pelos locais e épocas de cultura, uma vez que fatores como temperatura, umidade do ar, precipitação e fotoperíodo variaram com a estação do ano.

Houve efeito de interação entre a colheita e a época de sementeira das sementes (Quadro 3). A massa
Quadro 2-A) Comprimento da parte aérea (CPA), indice de velocidade de emergência (IVE) e porcentagem de emergência (EM) das safras 2013/2014 e 2014/2015 (colheita 1 e colheita 2 , respectivamente). (B) comprimento da parte aérea (CPA) de plântulas de feijão-caupi (Vigna unguiculata (L.) Walp) em duas épocas de sementeira (inverno e verão)

\begin{tabular}{cccc}
\hline A) Colheita & CPA (cm) & IVE & EM (\%) \\
\hline $2013 / 2014$ & $7,80 \mathrm{~b}$ & $4,08 \mathrm{a}$ & $87,40 \mathrm{a}$ \\
$2014 / 2015$ & $8,22 \mathrm{a}$ & $3,88 \mathrm{~b}$ & $81,02 \mathrm{~b}$ \\
\hline Médias & 8,01 & 3,98 & 84,21 \\
CV(\%) & 8,62 & 9,43 & 7,74 \\
\hline B) Sementeira & CPA (cm) \\
\hline Inverno & $7,73 \mathrm{~b}$ \\
Verão & $8,28 \mathrm{a}$ \\
\hline Médias & 8,01 \\
CV(\%) & 8,62 \\
\hline
\end{tabular}

Médias seguidas da mesma letra na coluna não diferem entre si pelo teste de F.

seca da parte aérea (MSPA) de plântulas analisadas no verão diferiu significativamente daquelas observadas no inverno para ambos os lotes das colheita 1 e 2, apresentando valores mais elevados. Constatou-se também divergência das médias entre os lotes na sementeira realizada no verão. 
Quadro 3 - Massa seca da parte aérea (MSPA) e massa seca da raiz (MSRAIZ) de plântulas de feijão-caupi (Vigna unguiculata (L.) Walp) oriundas das safras 2013/2014 e 2014/2015 (colheita 1 e colheita 2 , respectivamente) em função da época de sementeira (inverno e verão)

\begin{tabular}{cccc}
\hline \multirow{2}{*}{ Colheita } & \multicolumn{2}{c}{ MSPA (mg) } & \multirow{2}{*}{ Média } \\
\cline { 2 - 3 } & Inverno & Verão & \\
\hline $2013 / 2014$ & $75,84 \mathrm{aB}$ & $96,69 \mathrm{bA}$ & 86,265 \\
$2014 / 2015$ & $74,65 \mathrm{aB}$ & $119,13 \mathrm{aA}$ & 96,89 \\
Média & 75,245 & 107,91 & \\
CV(\%) & 8,10 & \multirow{2}{*}{ Média } \\
\hline \multirow{4}{c}{ MSR (mg) } & 43,73 \\
Colheita & Inverno & Verão \\
\hline 2013/2014 & $50,63 \mathrm{aA}$ & $36,83 \mathrm{bB}$ \\
$2014 / 2015$ & 46,99 aA & 42,83 aA & 44,91 \\
Média & 48,81 & 39,83 & \\
CV(\%) & 18,85 & & \\
\hline
\end{tabular}

*Médias seguidas da mesma letra minúscula na coluna e maiúscula na linha não diferem entre si, a $5 \%$ de probabilidade, pelo teste de Tukey.

Para a massa seca da raiz (MSR), quando se compararam as duas épocas de sementeira, observou-se acumulação de matéria seca superior para os dois lotes de colheita semeados no inverno, no entanto, não foram verificados entre eles valores significativamente diferentes, nesse período. No verão, registraram-se diferenças significativas entre os dois lotes. O que está de acordo com Yan e Holland (2010), que referem o efeito de fatores genéticos e ambientais, bem como a interação entre ambos, no desempenho diferencial da mesma cultivar em distintas condições ambientais.

O comprimento da raiz das plântulas foi influenciado significativa e diretamente pelas doses aplicadas de tiametoxame, como demostrado pelo modelo linear apresentado na Figura 1A. Os resultados indicam que a aplicação exógena do bioativador nas sementes promove o aumento do comprimento das raízes. De acordo com Almeida et al. (2009) a interação do bioativador com o potencial germinativo das sementes, estimula o crescimento das raízes de maneira mais rápida favorecendo o aumento da absorção de nutrientes pela planta. Esse efeito benéfico do tiametoxame sobre o comprimento da raiz das plântulas foi verificado por diversos autores em diferentes culturas, feijão-comum (Borges et al.,2015), algodão (Lauxen et al., 2010) e aveia-preta (Almeida et al., 2012).

Apesar do comprimento da raiz de plântulas de feijão-caupi aumentar significativamente com as doses de tiametoxame (Figura 1B), o material assimilado pelas raízes não apresentou desempenho semelhante. O efeito positivo na capacidade assimilatória de MSR promovido pelo tiametoxame foi constatado até a dose 0,24 g. i.a. por litro, sendo
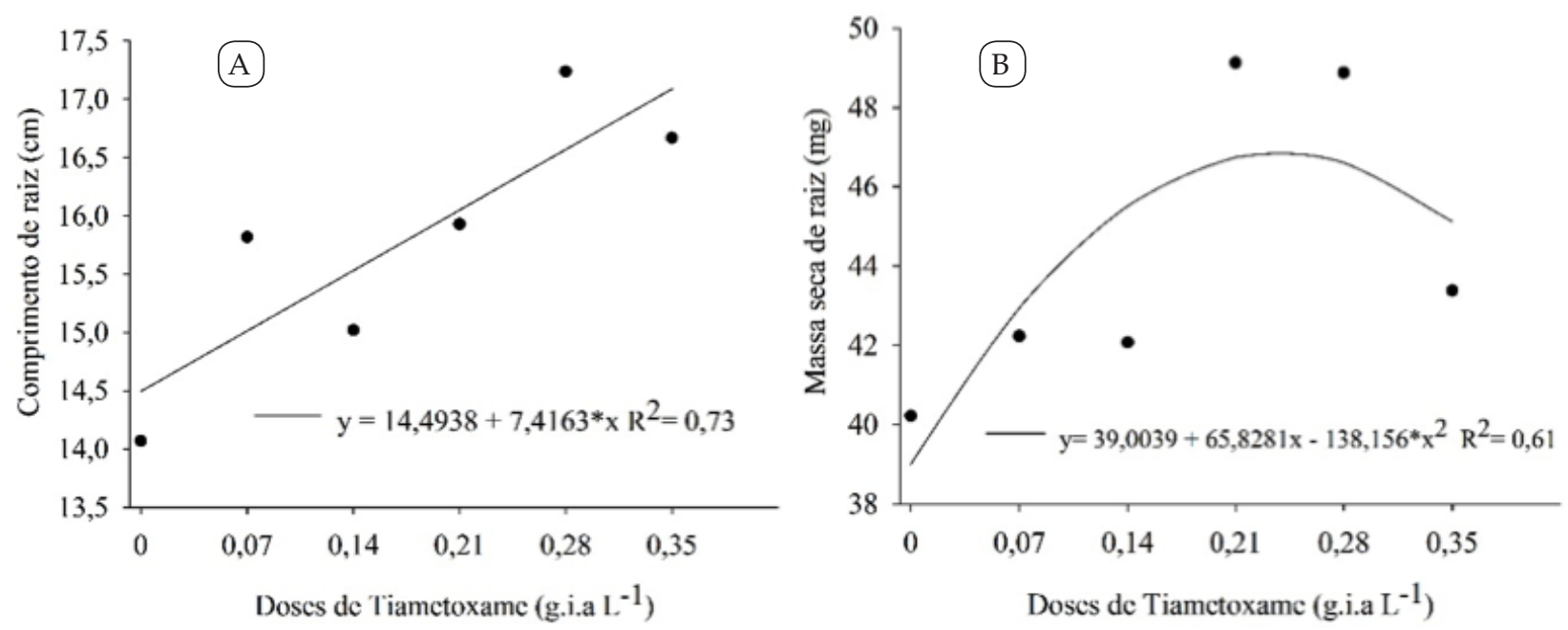

Figura 1 - A) Comprimento da raiz de plântulas e B) massa seca da raiz de plântulas de feijão-caupi (Vigna unguiculata (L.) Walp) em função das doses de tiametoxame. 

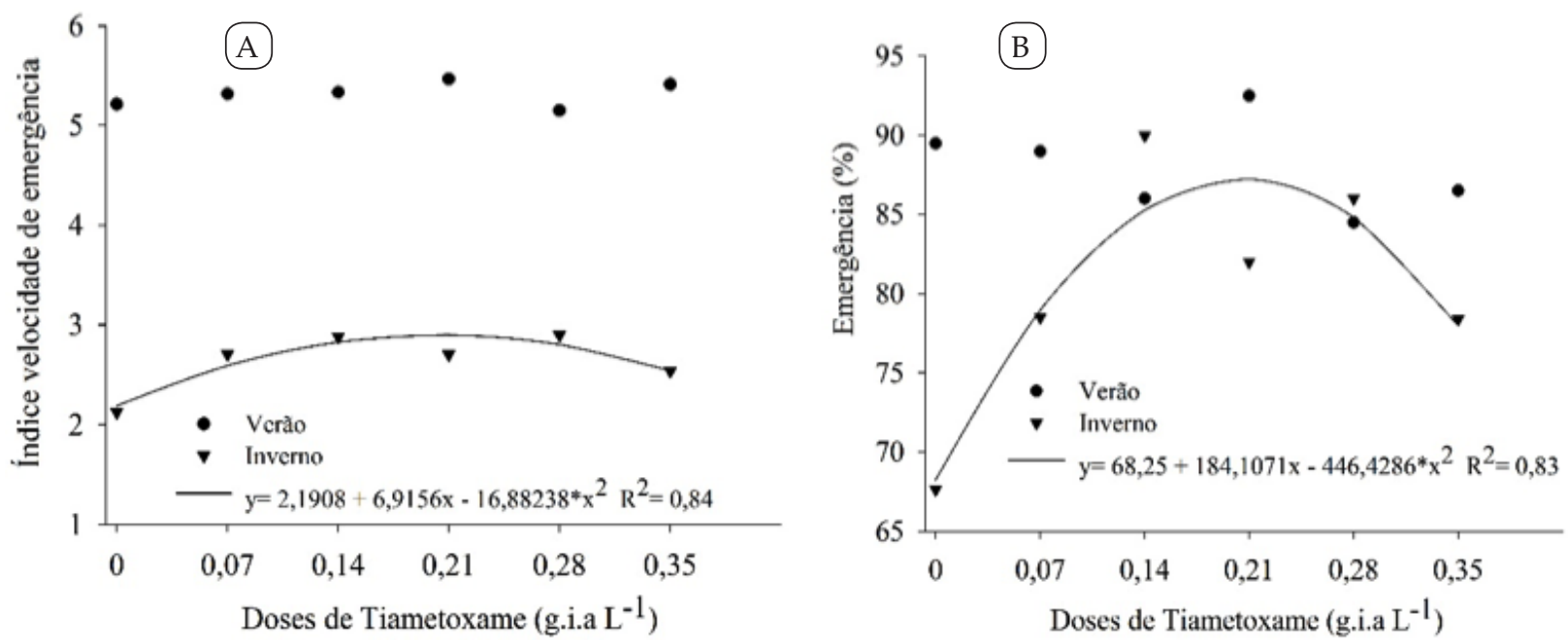

Figura 2 - A) Comprimento da raiz de plântulas e B) massa seca da raiz de plântulas de feijão-caupi (Vigna unguiculata (L.) Walp) em função das doses de tiametoxame.

esta a dose máxima para se obter incrementos, após esse ponto valores decrescentes foram verificados.

A interação entre as doses e a época de sementeira foi verificada para IVE e porcentagem de emergência quando realizada no inverno (Figura 2). No período de inverno, nem sempre as sementes encontram as condições ambientais favoráveis para germinar e, consequentemente, expressar o seu máximo vigor. Provavelmente o efeito do tiametoxame foi mais evidente nessa época por fornecer à plântula condições para superar a adversidade do ambiente. Perante o exposto, Tavares et al. (2007) discorrem que o tratamento de sementes com tiametoxame ativa várias reações fisiológicas, como síntese de proteínas de membrana, estimulando vários mecanismos de defesa, permitindo que a planta suporte melhor as condições ambientais adversas. Essa ideia é reforçada por Carvalho et al. (2014) relatando que o uso de produtos com propriedades bioativadoras pode estimular o crescimento das plantas dependendo da dose aplicada.

Observou-se que a dose máxima do produto comercial para se alcançar aumento na porcentagem de emergência na época de sementeira de inverno foi de $0,21 \mathrm{~g}$ i.a. de tiametoxame por litro, as doses superiores ensaiadas promoveram decréscimos no número de plantas emergidas no campo (Figura 2B). O incremento verificado até a dose máxima, obtida por meio do modelo de regressão quadrática, indica que o uso de tiametoxame possui efeito benéfico, estimulando as plântulas a se estabelecerem de maneira célere e homogenia. De acordo com Almeida et al. (2012), as sementes tratadas com tiametoxame aceleram a germinação pela ação do produto que estimula a atividade enzimática, o que propicia emergência mais uniforme e melhor desenvolvimento inicial, o que reforça os resultados encontrados neste estudo.

Apesar dos mecanismos de ação do tiametoxame não serem totalmente elucidados, autores como Castro e Pereira (2008) expõem que sementes de soja submetidas ao tratamento por este ingrediente ativo apontaram teores de aminoácidos, atividade enzimática e síntese de hormonas vegetais mais elevados, favorecendo uma melhor resposta das plantas a essas proteínas, e que esses eventos proporcionaram aumentos significativos na produção e redução do tempo de estabelecimento da cultura no campo, sendo mais tolerantes a fatores de estresse. Entretanto, de alguma forma a aplicação de doses acima da ideal na sementeira de inverno, que neste estudo foi de $0,21 \mathrm{~g}$ i.a. de tiametoxame por litro para a característica porcentagem de emergência, supostamente pode levar a uma redução drástica dos componentes que favorecem o efeito vantajoso do tiametoxame diminuindo sua efetividade no desenvolvimento inicial das plântulas em condições de estresse e como consequência ocasionando decréscimos na porcentagem de plântulas emergidas. 


\section{CONCLUSÕES}

O produto tiametoxame estimulou o desempenho fisiológico de sementes de feijão-caupi, ocorrendo efeitos positivos no crescimento e assimilação de matéria seca pelas raízes.
A utilização da 0,21 g i.a. de tiametoxame por litro no tratamento de sementes de feijão-caupi semeadas no inverno permitiu um desempenho inicial melhor e, um estabelecimento uniforme das plântulas.

\section{REFERÊNCIAS BIBLIOGRÁFICAS}

Acevedo, J.C. \& Clavijo, J. (2008) - Investigación agronômica em Colombia. In: Clavijo, J. (Coord.) Tiametoxam: Un nuevo concepto em vigor y produtivad. Bogotá, p. 41-91.

Aguero, J.A.P.; Vieira, R.D. \& Bittencourt, S.R.M. (1997) - Avaliação da qualidade fisiológica de sementes de cultivares de soja. Revista Brasileira de Sementes, vol. 19, n. 2, p. 255-260.

Almeida, A.S.; Villela, F.A.; Meneghello, G.E.; Lauxen, L.R. \& Deuner, C. (2012) - Desempenho fisiológico de sementes de aveia-preta tratadas com tiametoxam. Semina: Ciências Agrárias, vol. 33, n. 5, p. 1619-1628. http://dx.doi.org/10.5433/1679-0359.2012v33n5p1619

Almeida, A.S.; Tillmann, M.A. A.; Villela, F.A. \& Pinho, M.S. (2009) - Bioativador no desempenho fisiológico de sementes de cenoura. Revista Brasileira de Sementes, vol. 31 n. 3, p. 87-95. http://dx.doi.org/10.1590/ $\underline{\text { S0101-31222009000300010 }}$

Borges, C.T.; Almeida, A.S.; Deuner, C.; Jauer, A. \& Meneghello, G.E. (2015) - Efeito do tiametoxam no tratamento de sementes de feijão. Enciclopédia biosfera, Centro Científico Conhecer, vol. 11, n. 21, p. 898-907.

Brasil (2009) - Regras para análise de sementes. Ministério da Agricultura, Pecuária e Abastecimento. Secretária de Defesa Agropecuária, Brasília. 399 p.

Brito, M. de M.P.; Muraoka, T. \& Silva, E.C. da. (2009) - Marcha de absorção do nitrogênio do solo, do fertilizante e da fixação simbiótica em feijão-caupi (Vigna unguiculata (L.) walp.) e feijão-comum (Phaseolus vulgaris L.) determinada com uso de ${ }^{15 N}$. Revista Brasileira de Ciência do Solo, vol. 33, n. 4, p.895-905. http:// dx.doi.org/10.1590/S0100-06832009000400014

Castro, G.S.A.; Bogian, J.C.; Silva, M.G.; Gazola, E. \& Roselem, C.A. (2008) - Tratamento de sementes de soja com inseticidas e um bioestimulante. Pesquisa Agropecuária Brasileira, vol. 43, n. 10, p. 1311-1318. http:// dx.doi.org/10.1590/S0100-204X2008001000008

Castro, P.R.C. \& Pereira, M.A. (2008) - Bioativadores na agricultura. In: Gazzoni, D.L. (Ed.) - Tiametoxam: uma revolução na agricultura brasileira, p. 118-126.

Carvalho, L.S.M.J.; Rodrigues, H.C.S.; Meneghello, G.E.; Almeida, A.S. \& Navroski, R. (2014) - Desempenho fisiológico de sementes de feijão tratadas com produto bioativador. Enciclopédia Biosfera, Centro Científico Conhecer, vol. 10, n. 18, p. 1163-1172.

Carvalho, N.M. \& Nakagawa, J. (2012) - Sementes: ciência, tecnologia e produção. 5.ed. FUNEP, Jaboticabal. $590 \mathrm{p}$.

Cataneo, A.C. (2008) - Ação do tiametoxam (Thiametoxam) sobre a germinação de sementes de soja (Glycine $\max$ L.): Enzimas envolvidas na mobilização de reservas e na proteção contra situação de estresse (deficiência hídrica, salinidade e presença de alumínio). In: Gazzoni, D. L. (Coord.). - Tiametoxam: uma revolução na agricultura brasileira. Vozes, São Paulo. p.123-192.

Costa, R.Q.; Moreira, G.L.P.; Soares, M.R.S.; Vasconcelos, R.C. \& Morais, O.M. (2013) - Qualidade fisiológica de sementes de milho crioula e comerciais semeadas na região sudoeste da Bahia. Enciclopédia Biosfera, Centro Científico Conhecer, vol. 9, n. 16, p. 1873.

Ferreira, D.F. (2011) - Sisvar: A computer statistical analysis system. Ciência e Agrotecnologia, vol. 35, n. 6, p. 1039-1042. http://dx.doi.org/10.1590/S1413-70542011000600001

Freire Filho, F.R.; Ribeiro, V.Q.; Rocha, M.M.; Damasceno-Silva, K.J.; Nogueira, M.S.R. \& Rodrigues, E.V. (2011) - Feijão-caupi: produção, melhoramento genético, avanços e desafios. EMBRAPA Meio-Norte, Teresina. $81 \mathrm{p}$. 
Lauxen, L.R.; Villela, F.A. \& Soares, R.C. (2010) - Desempenho fisiológico de sementes de algodoeiro tratadas com tiametoxam. Revista Brasileira de Sementes, vol. 32, n. 3, p. 061-068. http://dx.doi.org/10.1590/ $\underline{\text { S0101-31222010000300007 }}$

Lemes, E.S.; Almeida, A.S.; Meneghello, G.E.; Tunes, L.M. \& Villela, F.A. (2015) - Germinação e vigor de sementes de abóbora tratadas com tiametoxam. Pesquisa Agropecuária Tropical, vol. 45, n. 1, p.122-127. http://dx.doi.org/10.1590/1983-40632015v4527581

Maguire, J. D. (1962) - Speed of germination-aid in selection and evaluation for seedling emergence and vigor. Crop Science, vol. 2, n. 1, p.176-177. http://dx.doi.org/10.2135/cropsci1962.0011183X000200020033x

Motta, I.S.; Braccini, A.L.; Scapim, C.A.; Inoue, M.H.; Ávila, M.R. \& Braccini, M.C.L. (2002) - Época de semeadura em cinco cultivares de soja. II. Efeito na qualidade fisiológica das sementes. Acta Scientiarum Agronomy, vol. 24, n. 5, p.1281-1286. http://dx.doi.org/10.4025/actasciagron.v24i0.2291

Peixoto, C.P.; Câmara, G.M.S.; Martins, M.C.; Marchiori, L.F.S.; Guerzoni, R.A. \& Mattiazzi, P. (2000) - Época de semeadura e densidade de plantas de soja: I. Componentes da produção e rendimento de grãos. Scientia Agricola, vol. 57, n. 1, p. 89-96. http://dx.doi.org/10.1590/50103-90162000000100015

Silva, A.C.; Morais, O.M.; Santos, J.L.; D'Arêde, L.O. \& Silva, P.B. (2014) - Componentes de produção, produtividade e qualidade de sementes de feijão-caupi em Vitória da Conquista, Bahia. Revista Agro@mbiente On-line, vol. 8, n. 3, p. 327-335. http://dx.doi.org/10.5327/Z1982-8470201400031894

Souza, L.C.D.; Yamashita, M.Y. \& Carvalho, M.A.C. (2007) - Qualidade de sementes de arroz utilizadas no norte de Mato Grosso. Revista Brasileira de Sementes, vol. 29, n. 2, p. 223-228. http://dx.doi.org/10.1590/ $\underline{\text { S0101-31222007000200029 }}$

Tavares, S.; Castro, P.R.C.; Ribeiro, R.V. \& Aramaki, P.H. (2007) - Avaliação dos efeitos fisiológicos de tiametoxan no tratamento de sementes de soja. Revista de Agricultura, vol. 82, n. 1, p. 47-54.

Yan, W. \& Holland, J.B.A. (2010) - Heritabilityadjusted G GE biplot for test environment evaluation. Euphytica, vol. 171, n. 3, p. 355-369. http://dx.doi.org/10.1007/s10681-009-0030-5 